\title{
A correta exegese do princípio da especialidade na solução do conflito aparente entre os tipos penais dos arts. 40 e 50-A da lei de crimes ambientais
}

\author{
Domingos Daniel Moutinho da Conceição Filho ${ }^{1}$
}

\begin{abstract}
This paper is an examination on the conflict between the rules found in articles 40 and 50-A of the Environmental Crimes Act. It mentions the Federal Courts understanding that adopts the concept of national parks (conservations units) as an element to define the Lex Specialis (Lex Specialis Principle). It reports the distortions and misunderstandings contained in that interpretation, and then argues that the normative element "public domain forest" should be the core of the rule supposed to be applied to the particular case. The author exposes, under many provisions of the Act that established art. 50-A and under the Superior Justice Court interpretation, the grounds for the understanding here supported, which rise, in essence, from the unambiguous terms used by the Law and from the obvious intention from the Parliament to protect public domain "forests", whether in protected areas or not. Furthermore, he formulates a case-by-case analysis, upon which mentions which rule must be applied in cases of degradation occurred in national parks or other preservation units, depending, essentially, on the kind of vegetation cover (forest or others) and on the domain of the area.
\end{abstract}

Key Words: Conflict between rules, Arts. 40 and 50-A Environmental Crimes Act., Lex Specialis Principle, National Parks (preservation units), Public domain forests.

\begin{abstract}
Resumo. Estudo sobre o conflito aparente de normas entre os tipos penais descritos nos artigos 40 e 50-A da Lei de Crimes Ambientais. Menciona o entendimento que utiliza o conceito de "unidades de conservação" como elemento a balizar o princípio da especialidade entre os tipos penais. Relata as distorções e equívocos contidos nesse entendimento, para, então, defender que o elemento normativo "floresta de domínio público" é que deve ser o cerne da eleição da norma aplicável ao caso concreto. Expõe, à luz dos diversos dispositivos da lei que instituiu o art. 50-A, da tramitação do projeto de lei que culminou na sua instituição e da jurisprudência do STJ, os fundamentos para o entendimento aqui apontado, os quais residem, em essência, nos inequívocos termos utilizados pelo tipo penal em questão e na manifesta intenção da lei em proteger as florestas de domínio público, estejam elas em unidades de conservação ou não. Por fim, formula uma análise casuística de qual tipo penal deve prevalecer no caso de degradações ocorridas em unidades de conservação, a depender, essencialmente, da espécie de cobertura florestal nelas contida e da dominialidade da unidade.
\end{abstract}

Palavras-chave: Conflito aparente de normas, Arts. 40 e 50-A da LCA, Princípio da Especialidade, Unidades de conservação, Florestas de domínio público.

\footnotetext{
${ }^{1}$ Possui graduação em Direito pela Universidade Federal do Pará (2007 Possui Especialização em Pós Graduação Lato sensu e Direito Processual Civil pela Universidade Anhanguera - Uniderp, Brasil(2010). Foi Técnico Judiciário do Tribunal Regional Eleitoral do Pará, Analista Judiciário do Tribunal Regional Federal da Primeira Região e Defensor Público Federal. Atualmente é Juiz Federal do Tribunal Regional Federal da $1^{\text {a }}$ Região , Brasil. E-mail: d.daniel.moutinho@gmail.com
} 


\section{Considerações Iniciais}

A jurisprudência pátria cada vez mais vem sendo instada a se manifestar sobre os delitos ambientais. No mesmo contexto, a doutrina se debruça sobre o tema com vistas a identificar eventuais incongruências do subsistema penal ambiental ante a desproporção de determinadas penas cominadas nos tipos penais descritos na Lei de Crimes Ambientais.

Em tempos de catástrofes ambientais cada vez mais frequentes e de franco avanço das distorções no clima do planeta, a própria comunidade internacional volta seus olhos com detida atenção aos mecanismos de proteção ao meio ambiente, inclusive no âmbito jurídico. Na seara penal, avançam as medidas de combate à devastação ambiental, seja por meio da instituição de novos tipos penais, seja por meio da correção das penas até então previstas, ante a flagrante irrisoriedade de algumas delas frente ao potencial poluidor das condutas que em tese seus tipos visam a punir.

É certo que em um país como o Brasil, onde a economia de subsistência segue sendo uma realidade, especialmente nos locais onde há necessidade de mais intensa tutela do meio ambiente, há imperiosa necessidade de observância de hipóteses de exclusão de ilicitude e/ou de culpabilidade de determinadas condutas. A par de tais situações, porém, o Direito Penal, ainda que tido em conta seu caráter fragmentário e subsidiário, necessita ser objeto de uso pelo Estado, como único mecanismo capaz de ao menos frear a devastação dos biomas mais sensíveis da biodiversidade brasileira.

O tema do presente estudo é absolutamente pertinente ao contexto até aqui apontado. $\mathrm{O}$ conflito aparente de normas decorrente do confronto entre os tipos descritos nos arts. 40 e 50-A da Lei 9.605/98, Lei Crimes Ambientais, é um retrato bastante ilustrativo de uma possível distorção no subsistema jurídico penal ambiental no que pertine à proporção entre a gravidade em tese dos ilícitos que tais dispositivos visam a combater e a sanção a eles cominada.

O que há de mais interessante nessa hipótese é que, ao contrário do que sói dizer a doutrina, desta vez a distorção não pode ser atribuída exclusivamente ao legislador. Há a necessidade, portanto, de aprofundamento dos estudos em torno do contexto do surgimento da mais recente normativa da tutela das florestas públicas e do objetivo da lei que a estabeleceu. A partir desse aprofundamento, fica claro que a interpretação do princípio da especialidade tradicionalmente tida em conta na definição da norma a ser aplicada no caso em debate, não se revela adequada, de vez que passa ao largo do âmago da proteção às florestas de domínio público. 


\section{O emprego do conceito de "unidades de conservação" enquanto balizador da apuração da norma especial no conflito entre os tipos penais dos arts. 40 e 50-A da Lei de Crimes Ambientais}

Os tipos penais em aparente conflito que são objeto do presente estudo visam, de acordo com seus respectivos elementos objetivos, subjetivos e normativos, a tutelar bens jurídicos bastante próximos. Ambos pretendem, em última instância, apesar do uso de vocábulos um tanto distintos, coibir a devastação de áreas naturais sem a devida autorização administrativa. O que os difere, porém, é, em essência, o local e a espécie de vegetação em face da qual a degradação tem lugar. Vejamos o que consta de cada um dos tipos penais em comento:

\footnotetext{
"Art. 40. Causar dano direto ou indireto às Unidades de Conservação e às áreas de que trata o art. 27 do Decreto $\mathrm{n}^{\circ}$ 99.274, de 6 de junho de 1990, independentemente de sua localização:

Pena - reclusão, de um a cinco anos"

"Art. 50-A. Desmatar, explorar economicamente ou degradar floresta, plantada ou nativa, em terras de domínio público ou devolutas, sem autorização do órgão competente:

Pena - reclusão de 2 (dois) a 4 (quatro) anos e multa."
}

Como dito, embora literalmente bastante distintos, ambos os texto normativos, concretamente, tipificam a degradação ambiental ocorrida sem a observância de seus requisitos e formalidades. Da análise dos tipos em questão, fica evidente o ponto de contato entre eles, que gera o conflito cuja solução aqui se debate. Ei-lo: no caso de degradações ocorridas no interior de unidades de conservação, conjugam-se elementos presentes no art. 40 (unidade de conservação) e no art. 50-A (terras de domínio público). Assim, qual seria, para essa hipótese, o modelo penal a ser tido em conta?

A resposta tradicionalmente apresentada pela jurisprudência adota, como elemento fulcral na definição dos critérios de especialidade entre os tipos penais, a identificação, como unidade de conservação, da área em que ocorrida a degradação. Assim, caso o ilícito tenha lugar em terras de domínio público não caracterizadas como tal (terras devolutas dos estados, glebas federais, áreas desapropriadas para fins de reforma agrária etc.), seu autor terá sua conduta capitulada no tipo do art. 50-A. Casa o ilícito ocorra em unidades de conservação, a subsunção da conduta será feita frente ao tipo do art. 40. Eis os precedentes que espelham esse entendimento:

PENAL E PROCESSUAL PENAL - RECURSO EM SENTIDO ESTRITO ART. 40, CAPUT, E 50-A DA LEI 9.605/98 - CONFLITO APARENTE DE NORMAS - PRINCÍPIO DA ESPECIALIDADE - NÃO RECEBIMENTO 
DA DENÚNCIA QUANTO AO ART. 50-A DA LEI 9.605/98 - RECURSO IMPROVIDO. I - A conduta de causar dano à Unidade de Preservação Permanente - Floresta Nacional (Flona Tapajós) - subsume-se ao disposto no art. 40, caput, da Lei 9.605/98. II - "Segundo a doutrina, em caso de conflito aparente de normas, a questão há de ser resolvida com a incidência dos princípios da sucessividade, especialidade, alternatividade, subsidiariedade e consunção (absorção).” (STJ, HC 56097/MG, 6 ${ }^{\mathrm{a}}$ Turma, Rel. Min. Og Fernandes, unânime, DJe de 07/12/2009). III - No caso dos autos, como a conduta tipificada no art. 50-A da Lei 9.605/98 - "desmatar, explorar economicamente ou degradar floresta, plantada ou nativa, em terras de domínio público ou devolutas, sem autorização do órgão competente" - encontra-se abrangida pela preceituada no art. 40, caput, da mesma lei, em face da prática de dano em Unidade de Conservação - Floresta Nacional (art. 40-A, $\S 1^{\circ}$, da Lei 9.605/98), aplica-se o princípio da especialidade, para afastar a incidência do disposto no art. 50-A da Lei dos Crimes Ambientais.

(RECURSO 00041518920114013902; RECURSO EM SENTIDO ESTRITO; Relator(a); DESEMBARGADORA FEDERAL ASSUSETE MAGALHÃES JUIZ FEDERAL MURILO FERNANDES DE ALMEIDA (CONV.); TRF1; TERCEIRA TURMA; e-DJF1 DATA:09/12/2011 PAGINA:570)

PROCESSUAL PENAL. UNIDADE DE CONSERVAÇÃO FEDERAL. FLORESTA NACIONAL. DESMATAMENTO. INCÊNDIO. ART. 40 E 40-A, $\S 1^{\circ}$, DA LEI 9.605/1998. DENÚNCIA. RECEBIMENTO PARCIAL. ARTS. 41 e 50-A DA LEI 9.605/1988. BIS IN IDEM. DESCABIMENTO. RECURSO DESPROVIDO. I - O art. 40 da Lei 9.605/1998 trata de preceito específico que visa a tutelar as Unidades de Conservação, nas quais, segundo o disposto no $\S 1^{\circ}$ do art. 40-A, estão incluídas as florestas nacionais. II - Desmatamento e incêndio de mata nativa em Unidade de Conservação, inserida na Floresta Nacional do Jamanxim, atraem a incidência dos arts. $40 \mathrm{c} / \mathrm{c}$ art. 40-A, $\S 1^{\circ}$, da Lei 9.605/1998, em razão do princípio da especialidade. Ficam afastados, portanto, os arts. 41 e 50-A da referida Lei, sob pena de se incorrer em bis in idem. III - Recurso em sentido estrito desprovido.

(RECURSO 00004829120124013902; RECURSO EM SENTIDO ESTRITO; Relator(a); DESEMBARGADOR FEDERAL CÂNDIDO RIBEIRO; TRF1; TERCEIRA TURMA; e-DJF1 DATA:19/04/2013 PAGINA:299)

\section{As distorções decorrentes da aplicação do conceito de "unidades de conservação" como critério para o Princípio da Especialidade (prevalência do art. 40)}

O grande problema da solução apontada no capítulo anterior reside no fato de que ela cria uma distorção tamanha, a ponto de subverter a lógica do subsistema penal ambiental quanto à proporcionalidade das reprimendas frente à gravidade em abstrato das condutas descritas nos tipos penais em discussão. Em termos práticos, a conduta, evidentemente mais grave, de degradar unidades de conservação é punida com menor rigor que a conduta de empreender devastação em terras públicas que não estão sob especial tutela do direito ambiental.

Isso porque a pena mínima prevista no preceito secundário do art. 40 é de apenas 1 ano, 
enquanto que a pena mínima para o crime do art. 50-A é de 2 anos. Quando se tem em conta que a quase totalidade das penas em concreto no direito penal é fixada no mínimo ou próximo a ele, a distorção revela-se absolutamente absurda, de vez que a conduta mais grave (degradação de florestas em unidades de conservação) acaba punida com a metade do rigor daquela menos grave (degradação de florestas fora de unidades de conservação).

O entendimento delineado no capítulo anterior parte da premissa de que, no direito penal, vale a legalidade estrita, assim, não poderia o magistrado aplicar pena mais grave que aquela rigorosamente prevista em lei, ainda que neste ponto o legislador pudesse ter sido incoerente. Tal premissa estaria correta não fosse o fato de que há um equívoco no critério tradicionalmente utilizado para a aplicação do princípio da especialidade na solução do conflito aparente de normas entre os arts. 40 e 50-A da Lei de Crimes Ambientais.

Não se pretende, no presente estudo, de forma alguma, sugerir a adoção de uma postura pragmática a fim de que a jurisprudência corrija, no âmbito de suas decisões, as distorções e desproporcionalidades pretensamente cometidas pelo legislador. É preciso frisar que os argumentos doravante defendidos partem de premissas absoluta e exclusivamente dogmáticas, pautadas pela análise dos elementos objetivos e normativos dos tipos penais bem como do contexto legal de sua instituição.

\section{O elemento normativo " "floresta" como correto cerne do princípio da especialidade no conflito entre os arts. 40 e 50-A da Lei de Crimes Ambientais}

O cerne da problemática do presente artigo reside no fato de que a conduta do agente que devasta a cobertura florestal em uma unidade de conservação de domínio público é passível de ser enquadrada, em tese, em qualquer um dos tipos penais previstos nos arts. 40 e 50-A da Lei 9.605/98. Isso porque a conduta em questão ostenta todos os elementos objetivos de ambos os dispositivos.

É que a quase totalidade das unidades de conservação previstas na Lei do 9.985/2000 (Lei do SNUC), à exceção da Reserva Particular do Patrimônio Natural, quando não estão totalmente

\footnotetext{
${ }^{2}$ Pode-se dizer que há certa controvérsia quanto à caracterização do termo "floresta" nos diversos tipos penais da LCA como elemento normativo. É que a dita expressão não demanda do julgador propriamente uma valoração, processo típico dos elementos normativos do tipo. Dela exsurge apenas uma necessidade de interpretação, como de tantos outros elementos meramente objetivos do tipo. De qualquer sorte, como o STJ, em diversos precedentes, se refere ao termo "floresta" como elemento normativo dos tipos dos crimes ambientais, este estudo assim também o designará, de modo que se abstrairá da discussão sobre este que é um tema de teoria geral do Direito Penal.
} 
Tabela 1.

\begin{tabular}{|c|c|c|}
\hline Conduta & Elemento do art. 40 & Elemento do art. 50-A \\
\hline $\begin{array}{l}\text { “...Tício devastou (...) } 250 \\
\text { Ha de terras, para fins de } \\
\text { implantar mais uma de suas } \\
\text { áreas de pasto ..." }\end{array}$ & $\begin{array}{l}\text { "Causar dano direto ou indi- } \\
\text { reto..." }\end{array}$ & $\begin{array}{l}\text { "Desmatar, explorar econo- } \\
\text { micamente ou degradar flo- } \\
\text { resta, plantada ou nativa..." }\end{array}$ \\
\hline $\begin{array}{l}\text { "...no interior da Floresta } \\
\text { Nacional do Tapajós..." }\end{array}$ & $\begin{array}{l}\text { "...às Unidades de Conser- } \\
\text { vação e às áreas de que trata } \\
\text { o art. } 27 \text { do Decreto }{ }^{\circ} \\
99.274 \text {, de } 6 \text { de junho de } \\
1990 . . .\end{array}$ & $\begin{array}{l}\text { "...em terras de domínio pú- } \\
\text { blico ou devolutas..." }\end{array}$ \\
\hline $\begin{array}{l}\text { "...sem o devido licencia- } \\
\text { mento ambiental..." }\end{array}$ & $\begin{array}{l}\text { Trata-se de elemento implí- } \\
\text { cito, já que o licenciamento } \\
\text { excluiria a ilicitude (exercí- } \\
\text { cio regular do direito). }\end{array}$ & $\begin{array}{l}\text { "...sem autorização do órgão } \\
\text { competente." }\end{array}$ \\
\hline
\end{tabular}

sob o domínio público, o estão quase que integralmente, apenas convivendo com propriedades privadas em caráter excepcional e sob determinadas condições. Em outras palavras, as "unidades de conservação" (art. 40) são, quase sempre, também, "terras de domínio público” (art. 50-A).

Nesse contexto, enfrentemos o seguinte exemplo: Tício devastou, no interior da Floresta Nacional do Tapajós, 250 Ha de terras, para fins de implantar mais uma de suas áreas de pasto, sem o devido licenciamento ambiental. Na autuação lá empreendida pelo IBAMA, houve constatação in loco do desmate. Apurados os fatos, os autos foram encaminhados ao MPF, que, então, propôs a correspondente ação penal. Pergunta-se, então, em qual tipo da Lei de Crimes Ambientais a conduta de Tício deve ser enquadrada? Deduz-se a presente demanda porque a conduta reúne, em tese, todos os elementos de ambos os tipos penais que são objeto deste estudo. Vejamos na Tabela 1

Como, no Direto, os conflitos entre normas sempre são somente aparentes, houve a necessidade de se socorrer no Princípio da Especialidade para a dedução de qual seria o modelo penal aplicável à espécie. Como demonstrado nos capítulos anteriores, há certa tendência em se utilizar, como critério para hipóteses análogas à utilizada aqui como exemplo, o elemento "unidade de conservação" para a solução da contenda, de modo a se fazer prevalecer o art. 40.

Aqui, porém, defende-se que a baliza a ser adotada para o Princípio da Especialidade no caso em exame deve ser o elemento normativo "floresta", presente no art. 50-A. E isto se diz não só porque o entendimento contrário implica nas distorções discriminadas anteriormente, mas também e, na verdade, essencialmente, porque essa parece ser a conclusão que se extrai da detida leitura dos tipos penais e da própria interpretação autêntica que se pode extrair da lei $n^{0} 11.284 / 2006$, que 
incluiu na Lei de Crimes Ambientais, o art. 50-A.

\subsection{O contexto da inovação legislativa que instituiu o art. 50-A}

O artigo 50-A foi inserido na Lei de Crimes Ambientais por meio da Lei ${ }^{0} 11.284 / 2006$, que teve por propósito disciplinar a gestão das florestas públicas e, assim, estabelecer parâmetros para sua implementação. Da leitura dos princípios entabulados no seu art. $2^{\circ}$, fica evidente que o escopo da referida lei residiu em conferir especial proteção às florestas de domínio público, ao tempo em que também visou à exploração sustentável, sob determinadas condições e observadas as categorias de utilização respectivas, desses espaços, seja pelo próprio poder público, seja pelas populações tradicionais ou pelos demais particulares.

No art. $3^{\circ}$ da lei 11.284/2006, consta, de maneira suficientemente clara, o conceito de florestas públicas: "florestas, naturais ou plantadas, localizadas nos diversos biomas brasileiros, em bens sob o domínio da União, dos Estados, dos Municípios, do Distrito Federal ou das entidades da administração indireta".

Desse conceito, observa-se que todas as florestas situadas em terras de domínio público devem ser consideradas "florestas públicas". Atente-se que a lei não as restringe àquelas situadas em terras públicas que não sejam consideradas unidades de conservação. Não há, portanto, razão para que a jurisprudência ou a doutrina o façam. Esta constatação é fundamental para o presente estudo.

\subsection{O conceito do STJ para o elemento normativo "floresta"}

Embora as leis ambientais remontem, constantemente, ao conceito de "floresta", tanto na esfera criminal, quanto na esfera cível-administrativa, não há uma definição legal para ele. Daí porque os precedentes do STJ o definem, em relação aos tipos penais ambientais, como um elemento normativo, aquele que demanda valoração pelo julgador.

Pois bem, a definição que o Superior Tribunal de Justiça elegeu, nos precedentes em questão, para o conceito de floresta é de todo simples e didática. Trata-se da "formação arbórea densa, de alto porte, que recobre área de terra mais ou menos extensa". Um dos precedentes a que mais se remetem a doutrina e as demais decisões do próprio STJ e das diversas Cortes de Apelação é o Habeas Corpus 74.950/SP, da relatoria do Ministro Felix Fischer. Embora se trate de feito que 
tinha por objeto o crime previsto no art. 38 da Lei de Crimes Ambientais, o fato é que tal conceito merece ser aplicado a todos os demais tipos penais que adotem o elemento normativo em questão. Vejamos, pois, a ementa do acórdão paradigma aqui mencionado:

PENAL. HABEAS CORPUS SUBSTITUTIVO DE RECURSO ORDINÁRIO. CRIME CONTRA O MEIO AMBIENTE. ART. 38, DA LEI No 9.605/98. EXTENSÃO DA EXPRESSÃO FLORESTA.

O elemento normativo "floresta", constante do tipo de injusto do art. 38 da Lei $n^{0} 9.605 / 98$, é a formação arbórea densa, de alto porte, que recobre área de terra mais ou menos extensa. O elemento central é o fato de ser constituída por árvores de grande porte.

Dessa forma, não abarca a vegetação rasteira. (Precedentes).

Habeas corpus concedido.

(HC 74.950/SP, Rel. Ministro FELIX FISCHER, QUINTA TURMA, julgado em 21/06/2007, DJ 10/09/2007, p. 269)

Da leitura da íntegra do voto condutor do acórdão, fica claro que o entendimento nele assentado se socorre da mais abalizada doutrina em matéria ambiental. Eis os excertos pertinentes do julgado aqui adotado como paradigma:

A exordial acusatória, em contrapartida, faz menção à destruição de vegetação rasteira nativa em estágio pioneiro inicial de regeneração, em área de preservação permanente (fl. 15). E tal vegetação não se ajusta à melhor definição de floresta. Esta, consoante doutrina abalizada, é a formação arbórea densa, de alto porte, que recobre área de terra mais ou menos extensa. O elemento central é o fato de ser constituída por árvores de grande porte. Nessa linha, tem-se o escólio dos seguintes autores: José Afonso da Silva (in Direito ambiental constitucional, $5^{\mathrm{a}}$ ed., Malheiros, 2004, p. 161), Paulo Affonso Leme Machado (in Direito ambiental brasileiro, $13^{\mathrm{a}}$ ed., Malheiros, 2005, p. 719), Vladimir Passos de Freitas e Gilberto Passos de Freitas (in Crimes contra a natureza, $7^{\text {a }}$ ed., RT, 2001, p. 114), Luiz Régis Prado (in Crimes contra o ambiente, $2^{\mathrm{a}}$ ed., RT, 2001, p. 103), Luís Paulo Sirvinkas (in Tutela penal do meio ambiente, $2^{\mathrm{a}}$ ed., Saraiva, 2002, p.145), Hely Lopes Meirelles (in Direito administrativo brasileiro, $28^{\mathrm{a}}$ ed., Malheiros, 2003, p. 540) etc.

Na hipótese trazida à lume, imputa-se à paciente a conduta de destruir vegetação rasteira. Tal fato, todavia, não se subsume ao tipo legal do art. 38 da Lei $n^{\circ}$ 9605/98 que, como visto, fala expressamente em floresta, em cujo conceito, repito, não se enquadra tal vegetação (rasteira).

Além do mais, é de se ressaltar que o Código Florestal (Lei n ${ }^{\circ} 4771 / 65$ ) não equipara a floresta com as demais formas de vegetação, mas muito pelo contrário, distingue-as. Pode-se mencionar, à título de exemplo, os seguintes dispositivos: Art. $1^{\circ}$ "As florestas existentes no território nacional e as demais formas de vegetação, reconhecidas de utilidade às terras que revestem, são bens de interesse comum a todos os habitantes do País, exercendo-se os direitos de propriedade, com as limitações que a legislação em geral e especialmente esta Lei estabelecem"(...), art. $2^{\circ}$ "Consideram-se de preservação permanente, pelo 
só efeito desta Lei, as florestas e demais formas de vegetação natural situadas:" (...). A própria Lei $\mathrm{n}^{\circ}$ 9605/98 cuidou de distinguir tais conceitos, consoante se depreende dos seguintes artigos: Art. 42. "Fabricar, vender, transportar ou soltar balões que possam provocar incêndios nas florestas e demais formas de vegetação, em áreas urbanas ou qualquer tipo de assentamento humano:" (...), Art. 48. "Impedir ou dificultar a regeneração natural de florestas e demais formas de vegetação:" (...), Art. 50. "Destruir ou danificar florestas nativas ou plantadas ou vegetação fixadora de dunas, protetora de mangues, objeto de especial preservação:" (...), Art. 51. "Comercializar motosserra ou utilizá-la em florestas e nas demais formas de vegetação, sem licença ou registro da autoridade competente:" (...) etc.

Fica, pois, evidente, que o conceito de "floresta" para fins penais não se confunde com todo e qualquer tipo de cobertura vegetal. Nesse sentido, somente os biomas caracterizados pela densidade e grande porte de sua vegetação poderão ser tidos como tal. O conceito aqui apreendido está no cerne do debate enfrentado no presente estudo.

\subsection{As unidades de conservação enquanto formas de exploração das florestas em terras de domínio público, de acordo com a lei instituidora do art. 50-A}

O presente capítulo talvez consista no epicentro de toda a discussão até aqui desenvolvida. Isso porque, em suas ponderações, pretender-se-á demonstrar, em suma, que a Lei 11.284/2006, ao inserir o art. 50-A na Lei de Crimes Ambientais, foi manifesta no sentido de procurar alcançar, nessa proteção, também as florestas situadas no interior de unidades de conservação.

A leitura detida dos dispositivos da Lei 11.284/2006 fornece ao julgador uma espécie de interpretação autêntica daquilo que o legislador pretendia tutelar. E a conclusão aqui defendida decorre do fato de que o referido diploma legal, por diversas vezes, remete à instituição e ao desenvolvimento de unidades de conservação como formas de exploração e utilização das ditas florestas públicas.

Aliás, o próprio parecer, na Câmara dos Deputados, do relator para o PL 4776/2005, que culminaria, posteriormente, na aprovação da Lei 11.284/2006, assenta expressamente que "a proposição prevê três modelos possíveis, complementares, para a gestão das florestas públicas: a criação das florestas nacionais, estaduais e municipais previstas pelo art. 17 da Lei 9.985/2000 (Lei do SNUC), geridas de forma direta; a destinação das florestas públicas às comunidades locais, na forma de reservas extrativistas, reservas de desenvolvimento sustentável ou projetos de assentamento florestal; e a concessão florestal".

Os termos utilizados pela Lei 11.284/2006 não deixam dúvidas e devem ser tidos, como já 
dito, como instrumentos de interpretação autêntica dos propósitos dos elementos essenciais do tipo penal do art. 50-A. Neste contexto, está, talvez, nos arts. $4^{\circ}$ e $6^{\circ}$ da referida lei, o cerne de todas as premissas interpretativas daquilo que deve ser considerado a título de "florestas (...) em terras de domínio público" para fins do tipo penal em debate. Os dispositivos legais aqui mencionados são deveras didáticos e, por isso, merecem integral reprodução:

Art. 4o A gestão de florestas públicas para produção sustentável compreende:

I - a criação de florestas nacionais, estaduais e municipais, nos termos do art.

17 da Lei no 9.985, de 18 de julho de 2000, e sua gestão direta;

II - a destinação de florestas públicas às comunidades locais, nos termos do art. 60 desta Lei;

III - a concessão florestal, incluindo florestas naturais ou plantadas e as unidades de manejo das áreas protegidas referidas no inciso I do caput deste artigo.

Já no inciso I do art $4^{\circ}$ fica evidente que a instituição de Florestas Nacionais, Estaduais e Municipais é umas das formas de gestão das florestas públicas. O inciso II do dispositivo supra, ao remeter ao art. $6^{\circ}$ da lei, acaba por também assentar que uma das modalidades de gestão das florestas públicas consiste na criação, nelas, de Reservas Extrativistas, de Reservas de Desenvolvimento Sustentável e das demais unidades de conservação de uso sustentável. É que o citado artigo remete expressamente a tais modalidades de unidades de conservação e, de modo transverso, a todas as demais modalidades, quando faz remissão expressa à Lei do SNUC e permite o uso de "outras formas previstas em lei":

Art. 6o Antes da realização das concessões florestais, as florestas públicas ocupadas ou utilizadas por comunidades locais serão identificadas para a destinação, pelos órgãos competentes, por meio de:

I - criação de reservas extrativistas e reservas de desenvolvimento sustentável, observados os requisitos previstos da Lei no 9.985, de 18 de julho de 2000; II - concessão de uso, por meio de projetos de assentamento florestal, de desenvolvimento sustentável, agroextrativistas ou outros similares, nos termos do art. 189 da Constituição Federal e das diretrizes do Programa Nacional de Reforma Agrária;

III - outras formas previstas em lei.

As Florestas Nacionais, Estaduais e Municipais são, sem dúvida, as unidades de conservação mais pertinentes frente aos objetivos da lei 11.284/2006, seja por conta de seus propósitos, seja por conta de seu nível de restrição à exploração. Elas são citadas, ainda, nos arts. 39, §1 ; 76; 78, II; e contam com uma seção específica para a sua disciplina na lei (arts. 48, caput e $\S \S)$.

De todo modo, fica claro que todas as demais unidades de conservação devem, também, ser tidas como contempladas pela tutela da lei 11.284/2006, desde que contenham em si florestas 
(“formação arbórea densa, de alto porte, que recobre área de terra mais ou menos extensa"). A uma, porque o já mencionado art. $6^{\circ}$ remonta a "outras formas previstas em lei", ao tempo em que se remete abertamente à lei do SNUC. A duas, porque a lei instituidora do art. 50-A da LCA menciona expressamente a quase totalidade das espécies de unidades de conservação nos incisos de seu art. 11, quando trata daquilo que deverá ser considerado na elaboração dos Planos Anuais de Outorga Florestal. Vejamos:

\footnotetext{
“Art. 11. O Paof para concessão florestal considerará:(...)

III - a exclusão das unidades de conservação de proteção integral, das reservas de desenvolvimento sustentável, das reservas extrativistas, das reservas de fauna e das áreas de relevante interesse ecológico, salvo quanto a atividades expressamente admitidas no plano de manejo da unidade de conservação; IV - a exclusão das terras indígenas, das áreas ocupadas por comunidades locais e das áreas de interesse para a criação de unidades de conservação de proteção integral";
}

Ora, se a própria lei determina que os PAOF excluam as florestas contidas em unidades de proteção integral das possíveis concessões, é porque seu propósito foi proteger de maneira ainda mais especial tais espécies de unidades e esse propósito necessita ser transposto para a interpretação do escopo de proteção do tipo penal previsto no art. 50-A. Enfim, toda e qualquer floresta situada em unidades de conservações em áreas de domínio público deve, pois, ser objeto da especial tutela do tipo penal em questão.

\subsection{A manifesta intenção do legislador em conferir especial proteção às florestas a par das demais formas de cobertura florestal, à luz da tramitação do projeto de lei que culminou na Lei 11.284/2005}

A intenção do legislador no sentido de conferir especial proteção às florestas a partir da instituição do tipo penal previsto no art. 50-A da LCA, a despeito de já restar evidente na leitura dos dispositivos da Lei 11.284/2005, passa a ser tida como inconteste se analisada a tramitação do projeto de lei que culminou na edição do referido diploma legal.

Diz-se isso, essencialmente, porque, quando o projeto de lei em questão (PL 4776/05 na Câmara e PLC 62/05 no Senado) foi encaminhado pelo Poder Executivo ao Congresso Nacional, propunha-se, em sua redação original, um conteúdo, para o art. 50-A da LCA (art. 82 da Lei 11.284), distinto daquele que viria a ser efetivamente aprovado pelo Parlamento. Vejamos a diferença no conteúdo das ditas proposições na tabela 2.

O cotejo entre as redações acima não deixa dúvidas: o legislador pretendeu, deliberada- 
Tabela 2.

\begin{tabular}{|c|c|}
\hline $\begin{array}{l}\text { Redação do PL encaminhado pelo Exe- } \\
\text { cutivo: }\end{array}$ & $\begin{array}{l}\text { Redação da Lei, tal como aprovada pelo } \\
\text { Legislativo: }\end{array}$ \\
\hline $\begin{array}{l}\text { Art. 83. Fica Acrescido o art. 50-A à } \\
\text { Lei } n^{0} \text { 9.605, de 1998, com a seguinte re- } \\
\text { dação: "Art. 50-A. Destruir ou danificar } \\
\text { vegetação nativa, plantada ou natural, } \\
\text { em terras de domínio público ou devolu- } \\
\text { tas, sem autorização do órgão competente } \\
\text { ou utilizá-la em desrespeito aos critérios ou } \\
\text { condicionantes estabelecidos na autoriza- } \\
\text { ção" }\end{array}$ & $\begin{array}{l}\text { Art. 82. A Lei no } 9.605 \text {, de } 12 \text { de fe- } \\
\text { vereiro de } 1998 \text {, passa a vigorar acrescida } \\
\text { dos seguintes arts. 50-A e 69-A: "Art. } \\
\text { 50-A. Desmatar, explorar economicamente } \\
\text { ou degradar floresta, plantada ou nativa, } \\
\text { em terras de domínio público ou devolutas, } \\
\text { sem autorização do órgão competente". }\end{array}$ \\
\hline
\end{tabular}

mente, conferir especial proteção às "florestas" a par das demais formas de cobertura florestal. E o propósito que motivou o Parlamento a adotar a modificação aqui observada milita no exato sentido de toda a proposição contida no presente artigo: fazer valer a especialidade do tipo penal recém instituído (art. 50-A) frente aos demais modelos penais da Lei de Crimes Ambientais, quando presente, no caso concreto, um contexto fático que se amolde ao elemento normativo "floresta".

As conclusões que aqui se extraem não são, nem de longe, arbitrárias. Isso porque o próprio parecer, aprovado na Câmara dos Deputados e que concluiu pela alteração redacional ora analisada, foi categórico ao registrar que a ideia, naquele contexto, era evitar eventuais conflitos com os demais tipos penais da LCA. Nesse sentido, o Relator do PL na Câmara, como justificativa para a alteração em questão, assentou o seguinte: "ajustar o tipo penal inserido na Lei de Crimes Ambientais (LCA), diante do conteúdo de outros tipos penais da própria LCA".

Sabe-se que na hermenêutica, há um brocardo segundo o qual verba cum effectu sunt accipienda (a lei não contém palavras inúteis). Assim, quando se ignora o elemento normativo "floresta", constante do tipo penal do art. 50-A da LCA, vai-se de encontro a esse postulado da interpretação. E isso se torna ainda mais evidente quando se observa que o legislador fez questão de inserir tal elemento no tipo para que servisse como especializador de sua conduta frente aos demais tipos da Lei de Crimes Ambientais.

\subsection{A lógica da proteção mais rigorosa das "florestas" frente a outras formas de cobertura vegetal}

As florestas, enquanto formas de cobertura vegetal de maior densidade e porte tendem a demandar mais tempo e necessitam conjugar uma sériemaior de fatores para o sucesso do processo de sua regeneração. Não raramente, a depender da profundidade e extensão do dano, faz-se 
necessário o uso da intervenção humana para auxiliar nesse processo ${ }^{3}$.

Embora o propósito do presente artigo não seja adentrar nos aspectos biológicos do processo de regeneração ecológica, da leitura superficial da literatura especializada, fica evidente que a regeneração de florestas é um processo especialmente sensível e complexo e que pode demandar diversos esforços para que sequer possa ser tido como viável.

Outrossim, sabe-se que as florestas exercem especial influência em diversos fatores ecológicos, como o ciclo das chuvas e a prevenção do solo. Assim, seja pela dificuldade na regeneração florestal, seja pelas influências que a floresta, de pé, é capaz de exercer, sua especial proteção é de todo justificada.

\section{Casuística das Unidades de Conservação frente ao art. 50-A da LCA}

Diante de todos os debates aqui consolidados, é válido demonstrar, a título ilustrativo, como se daria o enquadramento penal da degradação promovida nas seguintes unidades de conservação, conforme as características de sua cobertura florestal e sua titularidade. Vamos aos exemplos na tabela 3

\section{Conclusão}

De toda a argumentação desenvolvida no presente artigo, restam evidentes conclusões de todo simples, contudo, contundentes. O legislador, ao editar a Lei 11.284/2006 e, por meio dela, incluir na Lei de Crimes Ambientais o tipo penal previsto no art. 50-A, procurou conferir especial proteção às florestas situadas em terras de domínio público.

Ao conferir essa especial tutela, deixou a lei evidente que ela deve se referir a toda e qualquer floresta, assim considerada "a formação arbórea densa, de alto porte" (precedentes do STJ), desde que esteja situada em terras de domínio público. Fica claro, assim, que tais florestas especialmente tuteladas pelo 50-A devem ser tanto aquelas localizadas em unidades de conservação, diversas vezes citadas na Lei 11.284/2006, quanto aquelas situadas em outras terras de domínio público.

Excluir as florestas situadas em unidades de conservação da tutela do art. 50-A da Lei 9.605/98 significa não apenas subverter a lógica da proporcionalidade que deve reger a gravidade

\footnotetext{
${ }^{3}$ http://www.cpt.com.br/cursos-meioambiente/artigos/regeneracao-natural-das-florestas-e-sucessao-secundariadas-especies-arbustivo-arboreas
} 
Tabela 3.

\begin{tabular}{|c|c|c|c|}
\hline $\begin{array}{l}\text { UC Degra- } \\
\text { dada }\end{array}$ & $\begin{array}{l}\text { Características da Cobertura Flores- } \\
\text { tal }^{4}\end{array}$ & $\begin{array}{l}\text { Tipo Penal } \\
\text { Pertinente }\end{array}$ & Obs. \\
\hline $\begin{array}{l}\text { Floresta Naci- } \\
\text { onal do Tapa- } \\
\text { jós }\end{array}$ & $\begin{array}{l}\text { A FLONA do Tapajós abriga vários ti- } \\
\text { pos de florestas, quais sejam: 1) flo- } \\
\text { resta tropical densa com árvores emer- } \\
\text { gentes e relevo plano; 2) floresta tropi- } \\
\text { cal densa com árvores emergentes e re- } \\
\text { levo dissecado em colinas e ravinas; } 3 \text { ) } \\
\text { floresta tropical aluvial 4)floresta tropi- } \\
\text { cal aberta com palmeiras e cipós e re- } \\
\text { levo plano; 5) floresta tropical aberta } \\
\text { com palmeiras e cipós e relevo disse- } \\
\text { cado em colinas e ravinas e 6) florestas } \\
\text { secundárias. }\end{array}$ & Art. 50-A & $\begin{array}{l}\text { Das características de sua } \\
\text { cobertura florestal, fica evi- } \\
\text { dente que esta UC é mar- } \\
\text { cada pela presença de flores- } \\
\text { tas. Como, no mais, está sob } \\
\text { o domínio da União, o ele- } \\
\text { mentos do 50-A estão todos } \\
\text { presentes }\end{array}$ \\
\hline $\begin{array}{l}\text { Reserva } \\
\text { Extrativista } \\
\text { Tapajós } \\
\text { Arapiuns }\end{array}$ & $\begin{array}{l}\text { A tipologia vegetal predominante na } \\
\text { RESEX é de Floresta Ombrófila Densa, } \\
\text { (...). Esta fitofisionomia é caracterizada } \\
\text { por árvores de grande porte, presença } \\
\text { de lianas lenhosas e epífitas em abun- } \\
\text { dância. }\end{array}$ & Art. 50-A & $\begin{array}{l}\text { Das características de sua } \\
\text { cobertura florestal, fica evi- } \\
\text { dente que esta UC é mar- } \\
\text { cada pela presença de flores- } \\
\text { tas. Como, no mais, está sob } \\
\text { o domínio da União, o ele- } \\
\text { mentos do 50-A estão todos } \\
\text { presentes }\end{array}$ \\
\hline $\begin{array}{l}\text { Parque Nacio- } \\
\text { nal de Jerico- } \\
\text { acoara }\end{array}$ & $\begin{array}{l}\text { Grande parte da vegetação é decídua, } \\
\text { Há o predomínio de formações pio- } \\
\text { neiras herbáceas, constituídas predo- } \\
\text { minantemente por espécies psamófilas- } \\
\text { reptantes, destacando-se diversas legu- } \\
\text { minosas e gramíneas As plantas arbus- } \\
\text { tivas e arbóreas são menos frequentes } \\
\text {... }\end{array}$ & Art. 40 & $\begin{array}{l}\text { Com uma vegetação predo- } \\
\text { minantemente herbácea, não } \\
\text { se pode falar na presença de } \\
\text { "floresta", daí o enquadra- } \\
\text { mento no art. } 40 \text {. }\end{array}$ \\
\hline $\begin{array}{l}\text { Reserva } \\
\text { particular } \\
\text { do Patrimô- } \\
\text { nio Natural } \\
\text { Florescer }\end{array}$ & $\begin{array}{l}\text { A Floresta Ombrófila Mista (FOM) } \\
\text { também conhecida como floresta com } \\
\text { araucárias se distribui no Planalto Me- } \\
\text { ridional do Brasil e em refúgios situa- } \\
\text { dos nas serras do Mar e da Mantiqueira, } \\
\text { embora, em tempos pretéritos, tenha se } \\
\text { expandido até mais ao norte do país. }\end{array}$ & Art. 40 & $\begin{array}{l}\text { Aqui, embora presente o ele- } \\
\text { mento "floresta", já não há } \\
\text { "terras de domínio público", } \\
\text { por isso o enquadramento no } \\
\text { art. 40, que se contenta } \\
\text { com a caracterização da área } \\
\text { como unidade de conserva- } \\
\text { ção. }\end{array}$ \\
\hline
\end{tabular}


das sanções penais, como também, e principalmente, ir de encontro ao manifesto propósito do legislador responsável pela instituição do tipo penal aqui debatido.

\section{Referências}

OLIVEIRA, Andréa. CPT. Regeneração natural de florestas e sucessão secundária das espécies arbustivo-arbóreos. Disponível em: <http://www.cpt.com.br/cursosmeioambiente/artigos/regeneracao-natural-das-florestas-e-sucessao-secundaria-das-especiesarbustivo-arboreas>. Acesso em:15 mar. 2017.

INSTITUTO CHICO MENDES DE CONSERVAÇÃO DA BIODIVERSIDADE - ICMBIO. Disponível em: <http://www.icmbio.gov.br/portal/unidades-de-conservacao>.Acesso em:15 mar. 2017.

REVISTA ELETRÔNICA DE JURISPRUDÊNCIA. Portal do STJ - Superior Tribunal de Justiça. Disponível em <https://ww2.stj.jus.br/processo/revista/inteiroteor/?num_registro=200700110 074\&dt_publicacao=10/09/2007>. Acesso em:06 abr. 2017.

JURISPRUDÊNCIA UNIFICADA. Portal do CJF - Conselho da Justiça Federal. Disponível em $<$ https://www2.jf.jus.br/juris/unificada/>. Acesso em:24 abr. 2017. BRASIL. Lei 11.284, de 02 de março de 2006. Portal do Palácio do Planalto.Dispõe sobre a gestão de florestas públicas para a produção sustentável. Disponível em <http://www.planalto.gov.br/ccivil_03/_ato20042006/2006/lei/111284.htm>. Acesso em:03 mai. 2017.

BRASIL. Lei 9.605, de 12 de fevereiro de 1998. Portal do Palácio do Planalto. Dispõe sobre as sanções penais e administrativas derivadas de condutas e atividades lesivas ao meio ambiente.Disponível em: <http://www.planalto.gov.br/ccivil_03/leis/L9605.htm>. Acesso em: 03 mai. 2017.

BRASIL. Decreto 6.063, de 20 de março de 2007. Portal do Palácio do Planalto.Dispõe sobre a gestão de florestas públicas para a produção sustentável. Disponível em:<http://www.planalto.gov.br/ccivil_03/_Ato2007-2010/2007/Decreto/D6063.htm>. Acesso em: 03 mai. 2017.

BRASIL.Projeto de Lei da Câmara n. 62/2005. Portal do Senado Federal. Dispõe sobre a gestão de florestas públicas para a produção sustentável. Disponível em:<http://www25.senado.leg.br/web/atividade/materias/-/materia/74634>. Acesso em: 03 mai. 2017.

BRASIL. Projeto de Lei 4776/2005. Portal da Câmara dos Deputados Disponível em $<\mathrm{http}$ ://www.camara.gov.br/proposicoesWeb/fichadetramitacao?idProposicao=275322>. Acesso em: 03 mai. 2017. 